\title{
ANALISIS KARAKTERISTIK PENGGUNA BUS BSD LINK UNTUK DESAIN KORIDOR BARU MENGGUNAKAN MODEL PERMINTAAN PERJALANAN
}

\author{
Verdy Ananda Upa ${ }^{1,}$ ) , Rahmat Setyadi' ${ }^{2)}$ \\ 1,2Institut Teknologi Indonesia, Program Studi Teknik Sipil \\ email : ${ }^{1}$ verdy.ananda@iti.ac.id, ${ }^{2}$ rs.rahmat@iti.ac.id
}

\begin{abstract}
Bumi Serpong Damai (BSD) is one of self contained city in Jabodetabek district. Sinarmas as developer of BSD started to develope the Mass Rapid Transit which special operated on that. Concept of MRT has been operated in the form of Bus Rapid Transit. A new BRT corridor implementation need a Passenger Demand Prediction. Thus, a special BRT Passenger Demand Modelling Method for a new BRT Line need to be developed. This attempt needs knowledge on the Existing BRT User Trip Characteristics. BSD Link User Trip Characteristics Survey were executed on Corridor Sector 1.3 Greenwich Park, during morning peak hour. The result indicates that the BRT are used mainly for working (63\%) and schooling (37\%) trips, the BRT passengers are the previous public transport (45\%) and motorcycle (55\%) users. The trip origin zone is extended $1 \mathrm{~km}$ to the left and right of the BSD Link corridor, while the trip destination zone is extended 500 meters to the left and right of the BSD Link corridor. The embarking connecting trip modes are dominated by motorcycle (43\%) and walking trip (57\%), while the alighting connecting trip modes are dominated by motorcycle (16\%) and walking trip (84\%)
\end{abstract}

Keywords : BSD Link, trip characteristic, connecting trip modes, influence area, connecting trip characteristics

\begin{abstract}
ABSTRAK
Bumi Serpong Damai (BSD) merupakan salah satu kota mandiri di kawasan Jabodetabek. Sinarmas Land sebagai developer kawasan BSD telah memulai untuk membangun Angkutan Massal Cepat yang dioperasikan khusus di kawasan tersebut. Konsep Angkutan Massal Cepat yang dipilih berupa Bus Rapid Transit (BRT). Implementasi koridor baru membutuhkan adanya suatu Prediksi Permintaan Penumpang. Oleh sebab itu, suatu metode Pemodelan Permintaan Perjalanan Penumpang khusus untuk BRT koridor baru perlu dibangun. Upaya ini membutuhkan pengetahuan tentang karakteristik perjalanan pengguna BRT yang ada. Survei Karakteristik Perjalanan Penumpang BSD Link telah dilakukan untuk koridor BSD Link Sektor 1.3 Greenwich Park pada jam puncak pagi. Hasil survei tersebut menunjukkan bahwa BSD Link pada jam puncak pagi terutama digunakan untuk perjalanan kerja (63\%) dan sekolah (37\%). Para penumpang BSD Link tersebut sebelumnya adalah pengguna angkutan umum (45\%) dan sepeda motor (55\%). Zona asal pengguna BSD Link merupakan daerah 1 km di sebelah kiri dan kanan koridor, sedangkan zona tujuan pengguna BSD Link merupakan daerah 500 meter di kiri dan kanan koridor. Moda penghubung yang digunakan sebelum menaiki BSD Link didominasi oleh sepeda motor (43\%) dan jalan kaki (57\%) Sedangkan moda penghubung setelah turun dari BSD Link juga didominasi oleh sepeda motor (16\%) dan jalan kaki (84\%).
\end{abstract}

Katakunci : BSD Link, karakteristik perjalanan, moda penghubung, daerah pengaruh, karakteristik perjalanan penghubung

\section{PENDAHULUAN}

Bumi Serpong Damai (BSD) City merupakan salah satu kota satelit di kawasan Jabodetabek yang ditujukan untuk dapat menjadi kota mandiri, dimana semua fasilitas tersedia di lokasi tersebut, mulai dari kawasan industri, perkantoran, perdagangan, pendidikan, wisata, sekaligus perumahan. Seiring meningkatnya sektor ekonomi mengakibatkan mobilitas masyarakatnya juga ikut meningkat sehingga permasalahan dalam bidang transportasi umum menjadi hal yang patut diperhatikan untuk mensejahterakan kehidupan masyarakat. Bidang 
transportasi menjadi satu kesatuan yang memiliki pengaruh besar dalam bidang ekonomi, sosial budaya, maupun sosial politik. Pengembangan transportasi umum diperlukan untuk dapat mengurangi kemacetan, memperlancar arus lalu lintas, menjaga kualitas lingkungan serta terjangkau oleh semua lapisan masyarakat.

Di era pembangunan negara yang sedang meningkat ini, dibutuhkan jasa transportasi umum yang memadai. Salah satu transportasi umum yang beroperasi di kawasan BSD City selain Transjakarta, angkutan umum, dan KRL adalah BSD Link. BSD Link memiliki 4 rencana koridor yang akan dioperasikan untuk melayani perjalanan di kawasan BSD City. Adapun 4 koridor tersebut adalah koridor The Avani - Sektor 1.3, Terminal Intermoda - De Park, The Breeze - Aeon - ICE - The Breeze, Sektor 1.3 - Greenwich Park. Terdapat 2 koridor yang telah dioperasikan yaitu The Breeze - Aeon - ICE - The Breeze, dan Sektor 1.3 - Greenwich Park. Jadi, diperlukan prediksi permintaan perjalanan untuk pengembangan koridor baru, khususnya 2 koridor yang belum dioperasikan.

BSD Link hanya dioperasikan untuk koridor tertentu. Rute yang digunakan untuk keberangkatan dan kedatangan (kembali) tidak selalu sama untuk setiap koridor dari BSD Link. Sehingga, pemodelan untuk mengetahui daerah cakupannya dilakukan sepanjang koridor tersebut. Pengembangan metode prediksi permintaan perjalanan oleh Kementerian Perhubungan tidak sesuai untuk diaplikasikan pada kasus ini Metode Khusus untuk Pemodelan Permintaan Perjalanan dianggap perlu dikembangkan untuk mengatasi kasus ini.

Metode tersebut menimbulkan beberapa pertanyaan dasar yaitu berapa luas daerah cakupan dari koridor BSD Link? Siapa pengguna dari BSD Link? Apakah penggunanya hanya berasal dari pengguna angkutan umum (angkot) atau sepeda motor? Atau berasal dari pengguna moda transportasi yang lain? Sehingga diperlukan identifikasi terkait Karakteristik Pengguna BSD Link untuk dapat menjawab pertanyaan tersebut.

Penelitian ini menunjukkan hasil identifikasi karakteristik pengguna BSD Link pada koridor yang telah beroperasi khususnya koridor Sektor 1.3 Greenwich Park, yang diperlukan untuk desain koridor baru dengan menggunakan prinsip pemodelan permintaan perjalanan.

Pada umumnya, pemodelan transportasi terdiri atas 4 tahapan yaitu Bangkitan Perjalanan (Bangkitan dan Tarikan Perjalanan)/TG, Pemilihan Moda/MS, Distribusi Perjalanan/TD, dan Pembebanan Perjalanan/TA. Karena berbagai macam permasalahan yang dihadapi dan alasan praktis, maka sekarang dikenal 3 tipe umum pemodelan yaitu model langsung, model konvensional, dan model nonkonvensional. Setiap tipe pemodelan tersebut memiliki kelebihan dan kekurangan. Perihal terkait urutan pemodelan 4 langkah, pada umumnya dikenal 4 tipe urutan antara lain tipe 1 : TG/MS - TD - TA, tipe 2 : TG - MS TD - TA, tipe 3 : TG - TD/MS - TA, tipe 4 : TG - TD - MS - TA.

Terdapat 2 tipe urutan pemodelan transportasi yang memiliki kecenderungan dapat dikombinasikan, sehingga hasil penggabungannya diharapkan menjadi bentuk pemodelan yang paling sesuai dengan kasus ini. Untuk kasus yang berbeda diperlukan kombinasi yang berbeda pula.

Metode untuk memprediksikan permintaan perjalanan dari suatu angkutan umum telah dirumuskan oleh Direktorat Jenderal Perhubungan Darat. Permintaan perjalanan merupakan fungsi dari jumlah populasi masyarakat yang melakukan perjalanan, jumlah kepemilikan kendaraan, dan tingkat penggunaan kendaraan pribadi. 
Permintaan perjalanan dihitung untuk setiap halte. Daerah cakupan meliputi lebarnya 800 meter sepanjang koridor angkutan umum.

\section{METODE PENELITIAN}

Pertanyaan yang mendasar tentang Pemodelan Permintaan Perjalanan untuk desain koridor baru berkaitan dengan tipe dan urutan pemodelan serta kondisi lalu lintasnya. Jawaban dari pertanyaan tersebut sangat berhubungan dengan Karakteristik Pengguna BSD Link. Karakteristik utama fokus terhadap maksud perjalanan, moda transportasi yang digunakan sebelum beroperasinya BSD Link, daerah cakupan BSD Link (jarak titik asal ke halte keberangkatan BSD Link dan jarak titik tujuan dari halte pemberhentian BSD Link), moda transportasi yang digunakan untuk menjangkau halte keberangkatan dan tujuan BSD Link. Lebih lanjut, data Karakteristik Perjalanan yang juga dikumpulkan antara lain distribusi naik dan turun penumpang setiap halte sepanjang koridor BSD Link, serta distribusi penumpang setiap segmen jalan sepanjang koridor BSD Link.

Penelitian ini merupakan syarat agar dapat menghitung permintaan potensial untuk pengembangan koridor yang belum dioperasikan khususnya koridor
The Avani - Sektor 1.3. Oleh sebab itu, akan dilakukan analisis pendekatan terhadap koridor yang telah beroperasi, khususnya koridor Sektor 1.3 Greenwich Park. Koridor Sektor 1.3 Greenwich Park digunakan sebagai sampel untuk mengindentifikasi Karakteristik Pengguna BSD Link karena memiliki tipikal daerah pelayanan yang sama yaitu menghubungkan kawasan residensial dengan komersial (CBD). BSD Link koridor Sektor 1.3 - Greenwich Park disajikan pada Gambar 1.

Survei dilakukan pada jam puncak pagi pada Juni 2019. Sampel yang digunakan sebanyak \pm 20 penumpang untuk setiap arahnya. Dengan demikian, total sampelnya sebanyak 49 penumpang. Survei dilakukan dalam kurun waktu 2 hari. Karakteristik Pengguna BSD Link yang diperoleh antara lain maksud perjalanan, moda transportasi yang digunakan sebelum BSD Link beroperasi, penghubung perjalanan sebelum keberangkatan - halte keberangkatan dengan titik asal, jarak dan moda yang digunakan dari titik asal; serta penghubung perjalanan setelah halte pemberhentian - halte pemberhentian dengan titik tujuan, jarak dan moda yang digunakan ke titik tujuan.

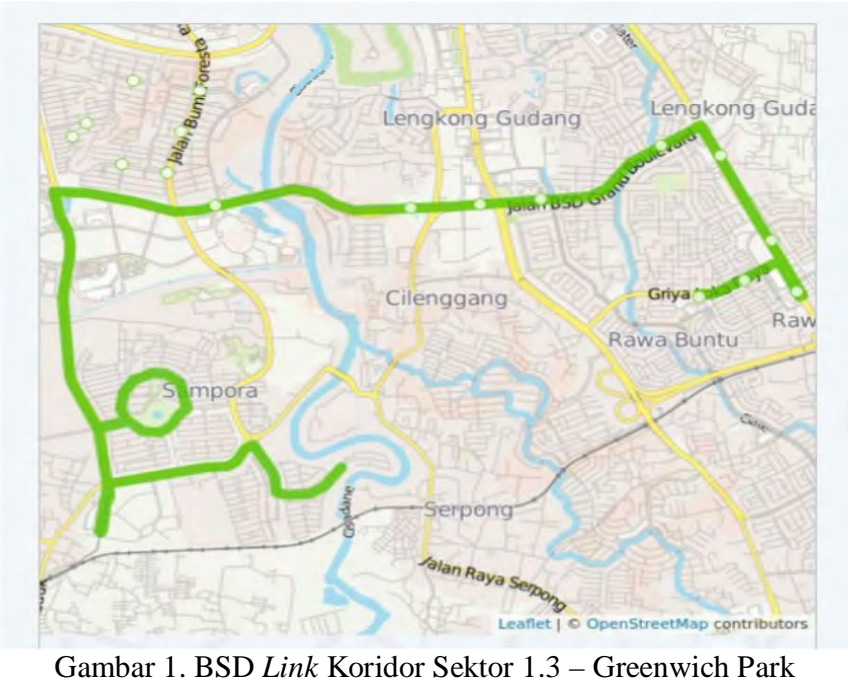


Verdy Ananda Upa dan Rahmat Setyadi, Analisis Karakteristik Pengguna... 


\section{HASIL DAN PEMBAHASAN}

Survei telah dilakukan dan data yang diperoleh dapat digunakan untuk dianalisis lebih lanjut sehingga menghasilkan beberapa poin tentang karakteristik yang dibutuhkan untuk pengembangan metode permintaan perjalanan. Poin utama karakteristik antara lain maksud perjalanan, moda transportasi yang digunakan sebelum BSD Link beroperasi, penghubung perjalanan - jarak dan moda transportasi yang digunakan. Dua karakteristik lainnya yang ditambahkan yaitu distribusi naik dan turun penumpang setiap halte serta distribusi penumpang setiap segmen jalan sepanjang koridornya. Berikut ini karakteristik utama yang akan dipaparkan.

\begin{tabular}{c|c|c|c|c|c}
\multicolumn{2}{c}{ Tabel 1. Maksud Perjalanan Pengguna BSD Link Koridor Sektor 1.3 - Greenwich Park } \\
\hline No & $\begin{array}{c}\text { Maksud } \\
\text { Perjalanan }\end{array}$ & $\begin{array}{c}\text { Sektor 1.3- } \\
\text { Greenwich } \\
\text { Park }\end{array}$ & $\begin{array}{c}\text { Greenwich } \\
\text { Park - Sektor } \\
1.3\end{array}$ & Jumlah & $\%$ \\
\hline 1. & Sekolah & 7 & 11 & 18 & 37 \\
\hline 2. & Bekerja & 13 & 18 & 31 & 63 \\
\hline
\end{tabular}

B. Moda Transportasi yang Digunakan

Sebelum BSD Link Beroperasi.

Fokus terhadap moda transportasi yang digunakan sebelum BSD Link beroperasi, hasil survei mengindikasikan bahwa 45\% dari total sampel merupakan pengguna angkutan umum (angkot) dan 55\% merupakan pengguna sepeda motor. Hasil ini menunjukkan bahwa BSD Link khususnya

\section{A. Maksud Perjalanan}

Berdasarkan hasil survei yang telah dilakukan mengindikasikan bahwa BSD Link koridor Sektor 1.3 - Greenwich Park pada jam puncak pagi pada umumnya digunakan untuk bekerja sebanyak 63\% dan sekolah sebanyak $37 \%$. Kedua hal tersebut merupakan jenis perjalanan yang dilakukan setiap harinya. Sehingga dapat disimpulkan bahwa pada jam puncak pagi, pengguna BSD Link merupakan pengguna aktif setiap hari. Pengguna BSD Link pada jam puncak pagi dapat dinyatakan dalam kondisi tetap. Hasil survei maksud perjalanan pengguna BSD Link koridor Sektor 1.3 - Greenwich Park disajikan pada Tabel 1.

koridor sektor 1.3 - Greenwich Park mampu memindahkan pengguna sepeda motor ke moda BSD Link. Hal tersebut berpengaruh terhadap pemodelan permintaan perjalanan. Survei pemodelan permintaan perjalanan tidak hanya fokus terhadap pengguna angkutan umum (angkot), melainkan pengguna sepeda motor juga. Hasil survei moda transportasi yang digunakan sebelum BSD Link beroperasi disajikan dalam Tabel

.Tabel 2. Moda Transportasi yang Digunakan Sebelum BSD Link Beroperasi

\begin{tabular}{c|c|c|c|c|c}
\hline No & Moda & $\begin{array}{c}\text { Sektor 1.3 - } \\
\text { Greenwich } \\
\text { Park }\end{array}$ & $\begin{array}{c}\text { Greenwich } \\
\text { Park - Sektor } \\
1.3\end{array}$ & Jumlah & $\%$ \\
\hline 1. & Angkot & 8 & 14 & 22 & 45 \\
\hline 2. & Sepeda Motor & 12 & 15 & 27 & 55 \\
\hline
\end{tabular}

C. Karakteristik Penghubung Perjalanan Untuk pengembangan desain model, daerah cakupan dan moda transportasi penghubung perlu untuk diidentifikasikan. Kedua hal tersebut menyatakan karakteristik penghubung 
perjalanan antara titik keberangkatan dan titik pemberhentian perjalanan. Jarak titik keberangkatan akan berpengaruh terhadap besarnya bangkitan perjalanan dari titik asal penumpang BSD Link. Sedangkan jarak titik pemberhentian akan berpengaruh terhadap besarnya tarikan perjalanan ke titik tujuan penumpang BSD Link. Moda transportasi penghubung juga penting untuk diketahui.

1) Karakteristik Penghubung Perjalanan - Sebelum Halte Keberangkatan

Survei sebelum halte keberangkatan menunjukkan bahwa jarak antara titik asal dengan halte keberangkatan beragam dari $0 \quad-1,0 \mathrm{~km}$. Perjalanan didominasi oleh $65 \%$ dari total sampel mengakses jarak antara $0-0,5 \mathrm{~km}$, dan $35 \%$ dari total sampel mengakses jarak antara 0,5 - 1,0 km. Sedangkan moda transportasi yang digunakan oleh penumpang untuk mengakses halte keberangkatan, 57\% berjalan kaki dan 43\% menggunakan sepeda motor. Hal ini menunjukkan bahwa daerah cakupan ke halte keberangkatan dapat mencapai jarak hingga $2 \mathrm{~km}$ sepanjang koridor BSD Link, dengan jarak $1 \mathrm{~km}$ sebagai daerah cakupan utama. Area dengan jarak $1 \mathrm{~km}$ sepanjang koridor BSD Link merupakan area bangkitan perjalanan utama dari BSD Link koridor Sektor 1.3 - Greenwich Park. Hasil survei disajikan dalam Tabel 3. Dan Tabel 4.

Tabel 3. Jarak antara Titik Asal dengan Halte Keberangkatan

\begin{tabular}{c|c|c|c|c|c}
\hline No. & Jarak (Km) & $\begin{array}{c}\text { Sektor 1.3- } \\
\text { Greenwich } \\
\text { Park }\end{array}$ & $\begin{array}{c}\text { Greenwich } \\
\text { Park - Sektor } \\
1.3\end{array}$ & Jumlah & $\%$ \\
\hline 1. & $0-0,5$ & 18 & 14 & 32 & 65 \\
\hline 2. & $0,5-1,0$ & 2 & 15 & 17 & 35 \\
\hline
\end{tabular}

Tabel 4. Moda Transportasi yang Digunakan dari Titik Asal ke Halte Keberangkatan

\begin{tabular}{c|c|c|c|c|c}
\hline No. & Moda & $\begin{array}{c}\text { Sektor 1.3- } \\
\text { Greenwich } \\
\text { Park }\end{array}$ & $\begin{array}{c}\text { Greenwich } \\
\text { Park-Sektor } \\
1.3\end{array}$ & Jumlah & $\%$ \\
\hline 1. & Jalan Kaki & 16 & 12 & 28 & 57 \\
\hline 2. & Sepeda Motor & 4 & 17 & 21 & 43 \\
\hline
\end{tabular}

2) Karakteristik Penghubung Perjalanan - Setelah Halte Pemberhentian

Survei setelah halte pemberhentian menunjukkan bahwa jarak antara halte pemberhentian dengan titik tujuan beragam dari $0-0,6 \mathrm{~km}$. Perjalanan didominasi oleh $53 \%$ dari total sampel mengakses jarak antara $0,3-0,6 \mathrm{~km}$, dan $47 \%$ dari total sampel mengakses jarak antara $0-0,3 \mathrm{~km}$. Sedangkan moda transportasi yang digunakan oleh penumpang untuk mengakses titik tujuan dari halte pemberhentian, 84\% berjalan kaki dan 16\% menggunakan sepeda motor. Hal ini menunjukkan bahwa daerah cakupan dari halte pemberhentian dapat mencapai jarak hingga $1 \mathrm{~km}$ sepanjang koridor BSD Link, dengan jarak 500 meter sebagai daerah cakupan utama. Area dengan jarak 500 meter sepanjang koridor BSD Link merupakan area tarikan perjalanan utama dari BSD Link koridor Sektor 1.3 - Greenwich Park. Hasil survei disajikan dalam Tabel 5. dan Tabel 6. 
Tabel 5. Jarak antara Halte Pemberhentian dengan Titik Tujuan

\begin{tabular}{c|c|c|c|c|c}
\hline No. & Jarak (Km) & $\begin{array}{c}\text { Sektor 1.3- } \\
\text { Greenwich } \\
\text { Park }\end{array}$ & $\begin{array}{c}\text { Greenwich } \\
\text { Park - Sektor } \\
1.3\end{array}$ & Jumlah & $\%$ \\
\hline 1. & $0-0,3$ & 9 & 14 & 23 & 47 \\
\hline 2. & $0,3-0,6$ & 11 & 15 & 26 & 53 \\
\hline
\end{tabular}

Tabel 6. Moda Transportasi yang Digunakan dari Halte Pemberhentian ke Titik Tujuan

\begin{tabular}{c|c|c|c|c|c}
\hline No. & Moda & $\begin{array}{c}\text { Sektor 1.3- } \\
\text { Greenwich } \\
\text { Park }\end{array}$ & $\begin{array}{c}\text { Greenwich } \\
\text { Park- Sektor } \\
1.3\end{array}$ & Jumlah & $\%$ \\
\hline 1. & Jalan Kaki & 17 & 24 & 41 & 84 \\
\hline 2. & Sepeda Motor & 3 & 5 & 8 & 16 \\
\hline
\end{tabular}

D. Distribusi Naik dan Turun Penumpang BSD Link Koridor Sektor 1.3 - Greenwich Park

Data naik dan turun penumpang yang telah diperoleh menyatakan karakteristik yang berkaitan dengan distribusi penumpang BSD Link. Titik keberangkatan BSD Link koridor sektor 1.3 - Greenwich Park dan sebaliknya terletak pada halte yang lokasinya dekat dengan kawasan pemukiman. Titik keberangkatan hampir selalu terletak pada halte yang lokasinya dekat dengan titik keberangkatan dari BSD Link. Di sisi lain, halte pemberhentian akan mendistribusikan penumpang, sehingga lokasi halte dekat dengan daerah perkantoran, sekolah, dan universitas. Titik pemberhentian hampir selalu terletak pada halte yang lokasinya jauh dari titik awal keberangkatan atau dekat dari titik akhir pemberhentian BSD Link. Hasil survei distribusi naik dan turun penumpang setiap halte sepanjang koridor BSD Link disajikan dalam Tabel 7.

Tabel 7. Data Naik dan Turun Penumpang BSD Link Koridor Sektor 1.3 - Greenwich Park

\begin{tabular}{|c|c|c|c|c|c|c|}
\hline \multirow{2}{*}{ No. } & \multirow[t]{2}{*}{ Halte BSD Link } & \multicolumn{2}{|c|}{$\begin{array}{c}\text { Sektor } 1.3- \\
\text { Greenwich Park }\end{array}$} & \multirow[t]{2}{*}{ Halte BSD Link } & \multicolumn{2}{|c|}{$\begin{array}{c}\text { Greenwich Park - } \\
\text { Sektor } 1.3\end{array}$} \\
\hline & & Naik & Turun & & Naik & Turun \\
\hline 1. & Sektor 1.3 & 3 & - & Greenwich Park & 5 & - \\
\hline 2. & Santa Ursula 1 & 2 & - & Foresta 1 & 3 & - \\
\hline 3. & Santa Ursula 2 & 3 & - & Naava Park 1 & 16 & - \\
\hline 4. & Santa Onderdil & - & - & SWA 2 & - & 3 \\
\hline 5. & Auto Part & - & - & Giant BSD & 2 & 3 \\
\hline 6. & Eka Hospital 2 & - & - & Eka Hospital 1 & 1 & 2 \\
\hline 7. & East Bussiness District & 10 & - & Puspita Loka & 2 & - \\
\hline 8. & SWA 1 & - & - & Polsek Serpong & - & - \\
\hline 9. & Green Cove & - & - & Ruko Madrid & - & 7 \\
\hline
\end{tabular}




\begin{tabular}{c|c|c|c|c|c|c}
\hline 10. & The Breeze & - & 9 & Pasar Modern & - & 2 \\
\hline 11. & Simpang Foresta & 2 & 3 & Griya Loka 1 & - & 2 \\
\hline 12. & FBL 5 & - & - & Sektor 1.3 & - & 10 \\
\hline 13. & Q Big & - & 5 & & & \\
\hline 14. & Greenwich Park & - & 3 & & & \\
\hline
\end{tabular}

E. Distribusi Jumlah Penumpang BSD Link Setiap Segmen Jalan Sepanjang Koridor Sektor 1.3 - Greenwich Park

Distribusi penumpang BSD Link pada segmen jalan sepanjang koridor Sektor 1.3 - Greenwich Park juga perlu untuk diketahui. Karakteristik ini dapat digunakan sebagai perbandingan data dengan hasil pemodelan permintaan perjalanan yang telah dilakukan. Analisis terhadap karakteristik ini didasarkan pada jumlah sampel yang diperoleh yaitu \pm 20 orang untuk setiap arah. Distribusi penumpang BSD Link sepanjang segmen jalan pada koridor Sektor 1.3 Greenwich
Park memiliki kesamaan untuk kedua arahnya. Jumlah penumpang terbanyak berada pada bagian tengah segmen jalannya. Jumlah penumpang paling banyak terlihat antara halte East Bussiness District - Green Cove untuk arah pertama (Sektor 1.3 - Greenwich Park) dan antara halte Eka Hospital 1 Ruko Madrid untuk arah yang kedua (Greenwich Park - Sektor 1.3). Haltehalte tersebut terletak pada kawasan bisnis di BSD City. Distribusi jumlah penumpang BSD Link pada segmen jalan sepanjang koridor Sektor 1.3 Greenwich Park disajikan dalam Gambar 2. dan Gambar 3.

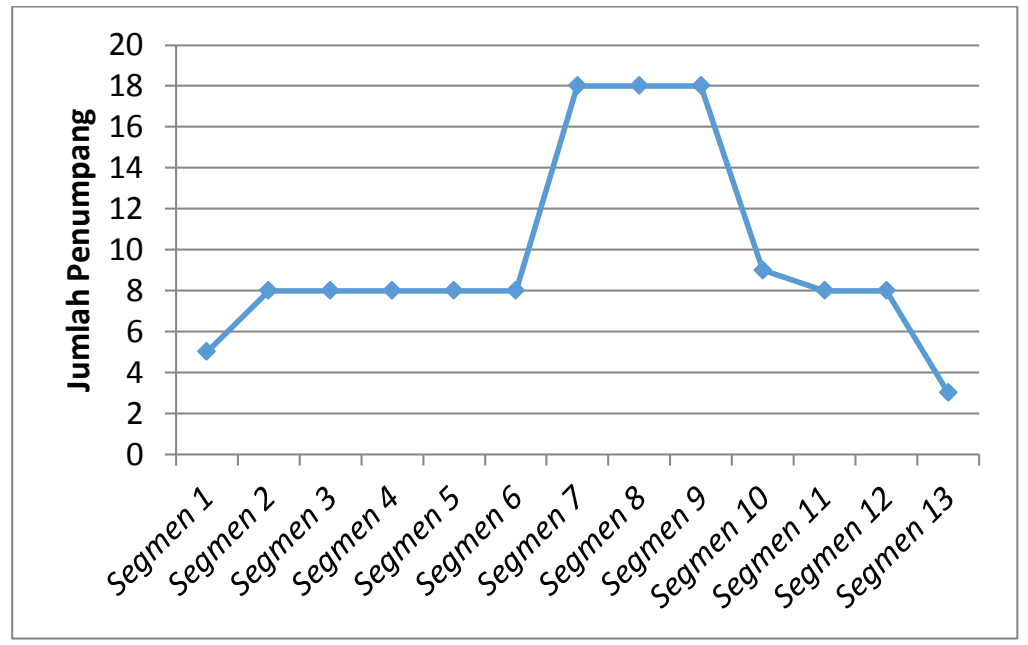

Gambar 2. Distribusi Jumlah Penumpang BSD Link Setiap Segmen Jalan Sepanjang Koridor Sektor 1.3 - Greenwich Park 




Gambar 3. Distribusi Jumlah Penumpang BSD Link Setiap Segmen Jalan Sepanjang Koridor Greenwich Park Sektor 1.3

\section{KESIMPULAN}

Sasaran penelitian ini telah terpenuhi. Beberapa poin yang dapat disimpulkan fokus terhadap karakteristik pengguna BSD Link koridor Sektor 1.3 Greenwich Park antara lain :

1. BSD Link koridor Sektor 1.3 Greenwich Park pada umumnya digunakan untuk bekerja dan sekolah di jam puncak pagi. Penumpang pada jam puncak pagi merupakan pengguna setiap harinya,

2. Moda transportasi yang digunakan oleh penumpang sebelum beroperasinya BSD Link koridor Sektor 1.3 - Greenwich Park yaitu $45 \%$ dari total sampel menggunakan angkutan umum dan 55\% menggunakan sepeda motor,

3. Zona bangkitan perjalanan mencapai jarak selebar 2 km sepanjang koridor, dengan 65\% bangkitan perjalanan berasal dari jarak selebar $1 \mathrm{~km}$,

4. Zona tarikan perjalanan mencapai jarak selebar 1 km sepanjang koridor, dengan 53\% perjalanan ke titik tujuan berjarak selebar $1 \mathrm{~km}$,

5. Moda transportasi penghubung utama antara titik asal dengan halte keberangkatan adalah jalan kaki dengan persentase sebesar 57\%. Sedangkan moda transportasi lainnya berupa sepeda motor dengan persentase $43 \%$,
6. Moda transportasi penghubung utama antara halte pemberhentian dengan titik tujuan adalah jalan kaki dengan persentase sebesar 84\%. Sedangkan moda transportasi lainnya berupa sepeda motor dengan persentase $16 \%$,

7. Titik keberangkatan BSD Link terdistribusi dari halte BSD Link hingga ke kawasan pemukiman,

8. Titik pemberhentian BSD Link terdistribusi dari halte BSD Link hingga ke titik tujuan seperti sekolah, kampus, dan perkantoran.

Data karakteristik pengguna BSD Link secara garis besar cocok untuk dikembangkan dalam suatu bentuk pemodelan permintaan perjalanan untuk desain koridor/rute baru dari suatu angkutan umum yang berbasis Bus Rapid Transit (BRT).

Survei yang sama dapat dilakukan untuk jenis angkutan massal cepat lainnya di kota yang berbeda, serta survei tersebut sangat diperlukan untuk membuat rencana dan studi kelayakan dari suatu angkutan massal cepat.

\section{DAFTAR PUSTAKA}

[1] C. Nugroho., 2013. “Aksesibilitas Halted an Kualitas Pelayanan Trans Jogja dengan Kepuasan Pengguna”, Universitas Negeri Yogyakarta. 
[2] J.D. Ortuzar and L.G. Willumsen., 1994. "Modelling Transport". Second Edition. New York : John Wiley \& Sons.

[3] J.V. Steijin., 2014., "Creating Feeder Bus Lines for Trans Jakarta $B R T$, Civil Engineering, University of Twente.

[4] Keputusan Direktur Jenderal Perhubungan Darat, No. SK. 687/AJ. 206/DRJD/2002., "Pedoman Teknis Penyelenggaraan Angkutan Umum Penumpang Umum di wilayah Perkotaan”.

[5] Kevin B. Modi, L.B. Zala, F.S. Umigrar \& T.A. Desai., 2011. "Transportation Planning Models : A Review". National Conference on Recent Trends in Engineering and Technology, Gujarat India.

[6] Ofyar Z. Tamin., "Perencanaan dan Pemodelan Transportasi”. Edisi ke2. Bandung : Institut Teknologi Bandung.

[7] R. Cervero, J. Murakami and M. Miller., 2009. "Direct Ridership Model of Bus Rapid Transit in Los Angeles Country Working Paper UCB-ITS-VWP-2009-3", Institute of Transportation Studies, University of California, Barkeley.

[8] Suprayitno H. \& Upa V.A., 2016. "Mamminasata BRT User Trip Characteristic for the Design of Demand Modelling Method for a New BRT Lines". IPTEK - The Journal for Technology and Science Vol. 27, Issue 3, December 2016, pp : 47 -52.

[9] Suprayitno, H. \& Upa, V.A., 2017. "Special Conventional Transport Model for a New BRT Line Passenger Demand Prediction". JTSS - Journal of Technology and Social Science, Vol. 1, Issue 3, 2017, pp : 10 -18.
[10]TASM Division Public Transport Assignment., 2014. "Transport Analysis Guidance (TAG) Unit M3.2. Department for Transport, London.

[11]Upa, V.A. \& Suprayitno, H. 2016. "Analisis Hubungan Antara Jumlah Naik dan Turun Penumpang dengan Tata Guna Lahan (Studi Kasus : Koridor 2 Trans Mamminasata)". Jurnal Ilmiah Gema Aktualita, Vol. 5 No. 2, Desember 2016.

[12]Upa V.A., 2017., "Perhitungan Jumlah Permintaan Potensial Bus Rapid Transit (BRT) Mamminasata Koridor 1 dengan Menggunakan Special Conventional Transport Model", Tesis Magister. Institut Teknologi Sepuluh Nopember.

[13] Upa, V.A. \& Suprayitno, H., 2018. "Perbandingan dan Sintesis Karakteristik Perilaku Perjalanan Pengguna Bis Trans Mamminasata dan Bis Trans Koetaradja”. Jurnal Manajemen Aset Infrastruktur dan Fasilitas Vol. 2, September 2018, pp : $69-82$.

[14]Upa, V.A. \& Setyadi, R. 2018. "Analisis Perpindahan Pengguna Moda Angkutan Umum (Lyn JSP) ke Moda Komuter Supor (Surabaya Porong) dengan Menggunakan Metode Logit Biner Selisih Waktu dan Biaya”. Jurnal Ilmiah Gema Aktualita, Vol. 7 No. 1, Juni 2018, pp : $\quad 10 \quad-\quad 15$. 
POLITEKNOLOGI VOL. 19 NO. 1 JANUARI 2020 
Verdy Ananda Upa dan Rahmat Setyadi, Analisis Karakteristik Pengguna... 